\title{
Slownik uniwersytecki niemiecko-polski jako wsparcie mobilności studentów
}

\section{German-Polish academic dictionary as a support for students' mobility}

Martyna Mikucka, Slawomir Krajka

Sekcja Translatoryczna Kola Naukowego

Studentów Lingwistyki Stosowanej

Uniwersytet im. Adama Mickiewicza

ul. 28 czerwca 1956 nr 198, 61-485 Poznań

\begin{abstract}
This article presents the results obtained by translating UNILEX Universitätswörterbuch für in- und ausländische Studierende by Prof. Burkhard Schaeder und Aleka Rapti from German into Polish by the Student Translator Association at the Institute of Applied Linguistics in Adam Mickiewicz University in Poznan. In the period of growing mobility among polish students who nowadays have great opportunities to study abroad, one of the most significant aspects of the student exchange is the ability to speak foreign languages. There are plenty of dictionaries, glossaries or guides available that can be helpful in helping students to get used to the education system in foreign universities, but they miss out important facts or not up-todate in most cases. Because of this fact the members of the Student Translator Association have come to the conclusion that translating the Unilex from German into Polish could become an advantage for polish students studying in Germany for a certain period of time.
\end{abstract}




\section{Czym jest Unilex?}

Slownik uniwersytecki Unilex Universitätswörterbuch für inund ausländische Studierende ('Unilex slownik uniwersytecki dla studentów niemieckich i zagranicznych') autorstwa Burkharda Schaedera i Aleki Rapti z Uniwersytetu w Siegen to niemiecki specjalistyczny slownik jednojęzyczny, którego celem zdefiniowanym przez jego autorów jest pomoc studentom niemieckim i zagranicznym w zrozumieniu terminów używanych w piśmie i mowie w szerokim kontekście studiów na niemieckiej uczelni (por. Schaeder, Rapti 2008: 7). Slownik zawiera okolo 1100 hasel wraz z definicjami, zebranych na podstawie tekstów związanych z systemem szkolnictwa wyższego w Niemczech. Warto zaznaczyć, iż co najmniej polowy tych hasel nie można znaleźć w ogólnodostępnych słownikach języka niemieckiego oraz slownikach przeznaczonych dla uczacych się języka niemieckiego jako obcego, należą tu przede wszystkim hasla uwzględniające najnowsze zmiany w strukturze niemieckiego szkolnictwa wyższego (np. Exzellenzinitiative, Globalhaushalt, Juniorprofessur). Makrostruktura slownika opiera się na znaczeniu opisywanych jednostek tj. slownictwo uporządkowano tematycznie według różnorodnych kategorii a słownik dodatkowo uzupelniono o alfabetyczny spis hasel z odnośnikami. Dzięki temu zabiegowi Unilex może posłużyć jako swoisty przewodnik dla swoich adresatów - polskich studentów zainteresowanych studiami w Niemczech. Umożliwi im bowiem, przy równoczesnym zachowaniu przejrzystości, wgląd w interesującą ich tematykę oraz szersze zapoznanie się $\mathrm{z}$ treścią danego dzialu.

\section{Po co polski przekład?}

Od kilku lat mamy do czynienia $\mathrm{z}$ rosnącą mobilnością studentów, glównie - choć nie tylko - w ramach programu Erasmus. Tylko w ubieglym roku na kierunku lingwistyka stosowana ze stypendium Erasmus skorzystało 49 studentów, w tym 40 wyjechalo do ośrodków 
uniwersyteckich w Niemczech ${ }^{1}$. Dane Uniwersytetu im. Adama Mickiewicza pokazuja, że to właśnie z niemieckimi szkołami wyższymi UAM posiada obecnie najwięcej umów bilateralnych w ramach programu Erasmus (aż 44, następna Francja: 27 umów i Hiszpania: 21 umów $^{2}$ ) a z liczby 850 studentów, którzy wyjechali w roku akademickim 2007/2008 na stypendia Erasmus aż 34\% wyjechało do Niemiec $^{3}$, także dane podsumowujacy 10-lecie programu Erasmus w Polsce jednoznacznie wskazują na to, że Polscy studenci najczęściej wyjeżdżali na studia do Niemiec (14 554 osoby) (do Francji (6647), Hiszpanii (4683), Wloch (4004) i Wielkiej Brytanii (3241) (Fundacja Rozwoju Systemu Edukacji, 2008). Jednocześnie badania przeprowadzone $w$ ramach prac magisterskich i licencjackich ${ }^{4}$ oraz opinie studentów powracających z pobytów w Niemczech mówiące o jednoznacznym sukcesie zarówno studentów jak i programu, wskazuja na zagrożenia z nim związane. Sa to: zbyt krótki pobyt aby móc odpowiednio zapoznać się ze strukturą uniwersytetu i jego obyczajami oraz tworzenie się spoleczności programu Erasmus żyjącej życiem odrębnym od rzeczywistości spoleczności uniwersytetu goszczącego (por. Turowska 2007: 75; Kroplewska 2008: 57). Pewną pomoc w przezwyciężaniu powyższych trudności moga stanowić publikacje Niemieckiej Centrali Wymiany Akademickiej: Wörterbuch Deutsch-Polnisch. Begriffe aus Wissenschaft und Hochschule. Stownik polsko-niemiecki. Slownictwo akademickie (Klugert, Wojciechowski 2001) oraz Kierunek Niemcy. Przewodnik dla zagranicznych studentów (Schmidt 2006).

Pierwszy jest jednak praktycznie niedostępny, drugi natomiast bardzo skrótowy, nie zawierajacy żadnego odniesienia do znanej studentowi polskiej rzeczywistości uniwersyteckiej. Można także wymienić wiele niemieckich stron internetowych zawierających

1 Dane wewnętrzne Instytutu Lingwistyki Stosowanej UAM, dostępne u instytutowego koordynatora programu Erasmus.

2 http://old.amu.edu.pl/erasmus/infole.php (28.04.2009).

3 Sprawozdanie z dzialalności programu Erasmus na Uniwersytecie im. Adama Mickiewicza w Poznaniu w roku akademickim 2007/2008, dane wewnętrzne UAM.

4 Kroplewska (2008), Turowska (2007) 
glosariusze terminologii uniwersyteckiej - dobór hasel nie jest jednak systematyczny a ich mikrostruktura wskazuje, że adresatem glosariuszy jest odbiorca rodzimy. Tak nakreślone potrzeby zwiazane z coraz intensywniejszą wymianą studentów z Niemcami przy jednoczesnym braku slowników, leksykonów czy innych narzędzi pozwalających studentom uczestniczącym w wymianie z Niemcami na szybkie i efektywne wlączenie się w życie spoleczności studenckiej uniwersytetu niemieckiego, skłoniło nas do podjęcia prac nad thumaczeniem slownika Unilex na język polski.

\section{Konstrukcja wersji polskiej}

Rozpoczynając pracę nad przekladem slownika Unilex napisaliśmy we wspólpracy z prof. Schaederem podręcznik (spis niezbędnych wytycznych leksykograficznych oraz informacji dotyczacych budowy i przekładu słownika), który stanowil dla nas podstawę w realizacji kolejnych prac thumaczeniowych. Nasz projekt prowadziliśmy w oparciu o stronę internetowa, która ulatwiała komunikację i koordynacje prac leksykograficznych. Na bieżaco uzupełnialiśmy slownik online, którego zasoby pozwalaly na utrzymanie jednolitości thumaczenia w trakcie calego projektu. Przed przystapieniem do prac thumaczeniowych doszliśmy do wniosku, iż dużym udogodnieniem dla adresatów naszego slownika byloby pozostawienie wersji niemieckiej w polskim przekladzie. Dzięki temu ostateczna wersja słownika będzie, w przeciwieństwie do oryginalu, dwujęzyczna. Będzie zatem składać się z części niemieckojęzycznej oraz polskojęzycznej, która będzie zawierala thumaczenie calości części niemieckojęzycznej wraz z ewentualnymi komentarzami kontrastywnymi. Wybór takiej formy slownika był nieprzypadkowy - jest to rzadko spotykana forma słownika fachowego dwujęzycznego, który bẹdac slownikiem thumaczeniowym (Übersetzungswörterbuch) jest nie tylko przeznaczony do użytku receptywnego (Rezeptionswörterbuch), lecz także do użytku produktywnego (Produktionswörterbuch). Ze względu na swąbudowę slownik może również okazać się przydatny dla tlumaczy. 
Szukając najwłaściwszych polskich ekwiwalentów, staraliśmy się precyzyjnie oddać znaczenie niemieckich haseł oraz równocześnie zwrócić uwagę odbiorców na ewentualne różnice wynikające z odrębności językowo-kulturowej. Niektóre polskie odpowiedniki, zwłaszcza te, które wydawaly nam się niepełnym ekwiwalentem niemieckiego terminu, opatrzyliśmy komentarzami kontrastywnymi. W szczególności wyrażenia nie zakorzenione w języku polskim, a w pewnym stopniu porównywalne z polskimi realiami, otrzymały stosowne komentarze. Dzięki temu zabiegowi odbiorca może spojrzeć na niemieckie realia z polskiej perspektywy, nie tracąc jednak z pola widzenia niemieckiej rzeczywistości.

\section{Problemy napotkane podczas thumaczenia}

W pierwszej części artykuly zostaly nakreślone cele oraz możliwości wykorzystania w praktyce powstającego slownika uniwersyteckiego niemiecko-polskiego. W tej części zaś zostaną przedstawione za pomocą trzech przykładów konkretne zadania thumaczeniowe oraz przykladowe trudności ze znalezieniem polskich ekwiwalentów.

\subsection{Przeklad stopni i tytulów naukowych i zawodowych na język polski}

Próba przetlumaczenia hasla Diplomkaufmann (Dipl.-Kfm.) na język polski spowodowala konieczność znalezienia odpowiedzi na kilka pytań:

- Czy można dokonywać tlumaczeń tytulów oraz stopni naukowych i zawodowych (ze względu na skutki dotyczące uznawalności wykształcenia)?

- Jeśli tak, to czy istnieje ekwiwalent niemieckiego stopnia akademickiego Diplomkaufmann (Dipl.-Kfm.)?

- Jeśli nie, w jaki sposób dokonać tlumaczenia?

Zalecenia dotyczące thumaczenia tytulów oraz stopni naukowych i zawodowych formulowane przez różne gremia (TEPIS. Kodeks 
Polskiego Tlumacza Sqdowego, Biuro Uznawalności Wyksztalcenia i Wymiany Międzynarodowej) są rozbieżne, odsylają często do wykazów tytulów oraz stopni naukowych i zawodowych publikowanych przez międzynarodowe lub krajowe cialo normotwórcze, których to wykazów niestety brak. Zalecenia informują zarazem, że w razie braku szukanego ekwiwalentu, thumacz może albo dokonać thumaczenia wedlug własnego uznania albo zachować dany tytuł lub stopień w brzmieniu oryginalnym (por. Kodeks Polskiego Ttumacza Sadowego § 38, §39). Ze względu na cel slownika postanowiliśmy dokonać thumaczenia, stosując strategię określoną w umowie między RP a RFN o uznaniu ekwiwalencji w szkolnictwie wyższym:

Należy używać tytulów i stopni naukowych zawsze w brzmieniu oryginalnym, z podaniem nazwy jednostki przyznającej; możliwie dosłowne tlumaczenie tytulów i stopni naukowych dołacza się ewentualnie w nawiasie. (art. 5 (3) umowy między między Rządem Rzeczypospolitej Polskiej a Rządem Republiki Federalnej Niemiec o uznaniu ekwiwalencji w szkolnictwie wyższym (Dz. U. z 1998 r. $\mathrm{Nr} 92$, poz. 584), tj. przetlumaczyć niemieckie stopnie akademickie możliwie dosłownie (zachowanie ich w brzmieniu oryginalnym nie byloby zgodne $z$ celem słownika). W pierwszym rzędzie należało stwierdzić, czy w Polsce istnieje odpowiednik niemieckiego stopnia akademickiego Diplom, który mógłby posłużyć za ekwiwalent.

Zestawienie polskich i niemieckich stopni akademickich

\begin{tabular}{|l|l|}
\hline JĘZYK POLSKI & JĘZYK NIEMIECKI \\
\hline $\begin{array}{l}\text { studia magisterskie jednolite } \\
\text { (magister) }\end{array}$ & $\begin{array}{l}\text { Magisterstudiengang (Magi- } \\
\text { ster) }\end{array}$ \\
\hline studia licencjackie (licencjat) & $\begin{array}{l}\text { Bacherlorstudiengang (Bache- } \\
\text { lor) }\end{array}$ \\
\hline $\begin{array}{l}\text { studia magisterskie uzupelnia- } \\
\text { jące (magister) }\end{array}$ & Masterstudiengang (Master) \\
\hline- & Diplomstudiengang (Diplom) \\
\hline
\end{tabular}


Jak wynika z porównania obu systemów ksztalcenia wyższego, w polskim systemie brakuje rodzaju studiów prowadzacych do uzyskania równoważnego tytulu zawodowego. Najbardziej zbliżonym kierunkiem studiów są studia magisterskie jednolite z możliwością uzyskania tytułu zawodowego magistra. Podanie jednak terminu magister jako odpowiednika Diplom byloby nieuzasadnionym stwierdzeniem równoważności tych dwóch tytułów, czego zasadniczo można dokonać jedynie w procedurze nostryfikacji. Dlatego stopień akademicki Diplom postanowiliśmy oddać za pomocą thumaczenia dyplomowany specjalista.

Znaczenie drugiego czlonu zlożenia Diplomkaufmann

\begin{tabular}{|l|l|}
\hline Kaufmann & kupiec \\
\hline 1.jmd., der [eine kaufmänni- & 1. osoba trudniąca się handlem \\
sche Lehre abgeschlossen hat & 2. potocznie o osobie kupują- \\
u.] beruflich Handel, Kauf u. & cej (SJP PWN) \\
Verkauf betreibt. (DUW) & Do 31.12.2000 r. pojęcie \\
Nach § 1 HGB ist Kaufmann, & kupca rejestrowego regulowal \\
wer ein Handelsgewerbe & kodeks handlowy, zgodnie \\
betreibt. (FStDP) & z którym kupcem rejestro- \\
& wym byla spólka handlowa. \\
& Od 2001 r. zamiast kupca (...) \\
& pojawila się definicja przed- \\
& siębiorcy. (FStDP) \\
\hline
\end{tabular}

Polska definicja, podobnie jak niemiecka, mówi, że kupiec to osoba trudniąca się handlem, niemiecka definicja wskazuje jednak dodatkowo, że jest to także osoba, która ma wyksztalcenie kierunkowe (choć nie jest to wymóg bezwzględny). Pozornie istnieje więc ekwiwalent w języku polskim (kupiec), jednakże po uwzględnieniu różnic w znaczeniu tych terminów nie możemy postawić między nimi znaku równości. Otóżjeśli zajrzymy do leksykonu specjalistycznego, to okaże się, że termin kupiec zostal w języku polskim w kontekście prawnym zastapiony terminem przedsiębiorca, który jednak nie określa zawodu, lecz jedynie status prawny danej osoby. Postanowiliśmy zatem zapoznać się z programem 
studiów prowadzących w Niemczech do uzyskania stopnia akademickiego Diplomkaufmann i na tej podstawie doszliśmy do przekonania, że jest on najbliższy polskim kierunkom ekonomicznym (ekonomika przedsiębiorstw), po których ukończeniu można wykonywać zawód ekonomisty, dlatego zaproponowaliśmy dla terminu Diplomkaufmann thumaczenie ekonomista dyplomowany.

\subsection{Konieczność uwzględniania kontekstu kulturowego w tlumaczeniu}

Kolejny aspekt, który chcielibyśmy poruszyć w oparciu na doświadczeniach zebrane podczas przekładu słownika Unilex, wiąże się z potrzebą uwzględnienia kontekstu kulturowego podczas tlumaczenia. Za przykład posłuży hasło numerus clausus.

Znaczenie hasla numerus clausus w języku polskim i niemieckim

\begin{tabular}{|l|l|}
\hline JEZZYK POLSKI & JĘZYK NIEMIECKI \\
\hline numerus clausus lac., liczba & Numerus clausus, der; -, o.PI. \\
ograniczona, wielkość ozna- & (Abk.: NC) (auch: Zulassungs- \\
czona maksymalną liczbą a. & beschränkung): Regelung, die \\
odsetkiem kandydatów pewnej & in bestimmten Studiengängen \\
kategorii (jak np. narodowoś- & die Zahl der $\rightarrow$ Studienplätze be- \\
ciowej, rasowej, klasowej), & schränkt. Für den Fall, dass die \\
którzy mogą być przyjęci na & Zahl der $\rightarrow$ Studienbewerber und \\
studia wyższe, do stowarzy- & Studienbewerberinnen größer \\
szeń, do pracy w urzędach. & ist als die Zahl der vorhandenen \\
(SWO) & Studienplätze, entscheidet ein $\rightarrow$ \\
& Auswahlverfahren. Für ausländi- \\
& sche Studienbewerber und Stu- \\
& dienbewerberinnen gelten Son- \\
& derregelungen (Quoten). Interner \\
& NC: innerhalb einer Hochschule \\
& und nicht bundesweit geltender \\
& NC. (Schaeder/Rapti 2008) \\
\hline
\end{tabular}


Zapoznawszy się z definicjami slownikowymi tych terminów w języku polskim i niemieckim, można dojść do wniosku, iż są one prawie identyczne. Pozornie istnieje więc ekwiwalent w języku polskim, jednakże należy szczególnie w tym przypadku zwrócić uwage na kontekst kulturowy, który postaramy się Państwu wyjaśnić przy pomocy szerszego zarysu historycznego.

Dzisiejsze znaczenie zasady numerus clausus w Niemczech wyksztalcilo się pod wplywem reform lat $60 / 70$. Zostaly one podjęte ze względu na rozgorzalą wówczas dyskusję spoleczną dotyczaca pogarszającego się stanu szkolnictwa, w tym także szkolnictwa wyższego. Dyskusja intensyfikowana nastrojami spolecznymi (protesty studenckie 68) zaowocowala przeprowadzeniem reform szkolnictwa na wszystkich szczeblach. W polowie lat 70 zabrakło środków finansowych na wdrożenie kolejnych reform. Brak wystarczajacych funduszy oraz odpowiedniej kadry nauczycieli akademickich, przy jednocześnie bardzo dużej liczbie abiturientów, spowodowal, iż postanowiono w semestrze zimowym 1976/77 wprowadzić zasadę ograniczeń rekrutacyjnych na wybranych kierunkach w celu utrzymania jakości ksztalcenia (medycyna, stomatologia, farmacja, psychologia, biologia).

Inaczej rysuje się historia numerus clausus w Polsce (oraz innych krajach Europy Środkowo-Wschodniej). Zasada wyznaczania numerus clausus należała wprawdzie zawsze do fundamentów nauki akademickiej, ale zwlaszcza w okresie międzywojennym motywowana była przyczynami politycznymi i religijnymi. W sposób szczególny chodzilo o wprowadzenie ograniczeń wobec kandydatów na studia pochodzenia żydowskiego. Mimo licznych sprzeciwów oświeconych warstw spoleczeństwa, niektóre uniwersytety przyjęly 1937 roku 10\% limit przyjęć dla kandydatów wyznania mojżeszowego, zgodny z udzialem ludności żydowskiej w kraju. Wprowadzenie zasady numerus clausus było podyktowane wzrostem nastrojów nacjonalistycznych i antysemickich. W okresie powojennym polityczny wymiar tej zasady widoczny był w przyznawaniu punktów kandydatom $z$ pochodzeniem robotniczo-chlopskim. Nie określano jej wtedy jednak expressis verbis mianem numerus clasus.

Śledząc okoliczności, w jakich rozwijal się termin numerus clau$s u s$, widać wyraźnie, iż zyskał on dopiero w okresie międzywojen- 
nym pejoratywne zabarwienie. Dziś zasada numerus clasus znajduje odzwierciedlenie w ograniczeniach rekrutacyjnych, które jednak nie mają charakteru politycznego, religijnego a jedynie merytoryczny. Nie nosi nazwy numerus clausus, która budzi negatywne konotacje (por. Natkowska 2006).

Wobec powyższego konieczne bylo znalezienie innego polskiego ekwiwalentu dla niemieckiego terminu numerus clausus, który nie bylby obciążony kulturowo i nie budzilby negatywnych konotacji. Szukając odpowiedniego ekwiwalentu posłużyliśmy się terminologią stosowaną dziś w dokumentach uczelni wyższych. Po opatrzeniu thumaczenia stosownym komentarzem kontrastywnym zaproponowane przez nas polski odpowiednik brzmi: limit przyjęć.

\subsection{Poprawność polityczna $\mathrm{w}$ dyskursie edukacyjnym}

Kolejną kwestią, którą chcielibyśmy omówić w oparciu na doświadczeniach zebranych podczas thumaczenia slownika uniwersyteckiego Unilex jest problem poprawności politycznej w dyskursie edukacyjnym. Wedlug definicji zawartej w slowniku Langzeitstudierender to „osoba studiująca dlużej o bliżej nieokreśloną liczbę semestrów niż trwa przewidziany regulaminem okres studiów" (Schaeder, Rapti 2008 - tlum. S.K.). Można by ją określić jako wiecznego studenta, co również znajduje swoje odzwierciedlenie w języku niemieckim w formie ewiger Student. Brzmiący neutralnie termin Langzeitstudierender został jednak ukuty jako norma obyczajowa specjalnie na potrzeby dyskursu publicznego, gdyż temat ten wzbudzal w ostatnich latach w Niemczech wiele kontrowersji. Wielu studentów wydluża bowiem pro forma okres studiowania, chcąc jak najdlużej korzystać z przyslugujących im ulg i niższych stawek podatkowych. Studenci ci jednak nie chcą być stawiani w negatywnym świetle w dyskursie publicznym przez użycie pejoratywnie lub ironicznie nacechowanego terminu na ich określenie. Stąd termin Langzeitstudierender wprowadzono celowo, kierujac się kanonami poprawności, aby uniknać negatywnych skojarzeń. Przekladając hasło Langzeitstudierender musieliśmy znaleźć w języku polskim ekwiwalent o wydźwięku neutralnym, który wpasowalby 
się w ramy odpowiednie dla wymagań dyskursu publicznego. Dodatkowym utrudnieniem był brak takiego zjawiska w Polsce, ponieważ studia dzienne oblożone są oplatami po przekroczeniu sześciu lat studiów, co uniemożliwia wykorzystanie podobnych luk prawnych. Zaproponowany przez nas ekwiwalent brzmi zatem następująco: student przekraczajacy standardowy okres studiów. Jest to termin opisowy, pozbawiony negatywnego zabarwienia oddajacy ideę poprawności politycznej oraz obrazujący problem zaistniały w szkolnictwie wyższym w Niemczech.

W trakcie thumaczenia slownika natrafiliśmy na problemy również innej natury, byly to $\mathrm{m}$.in. kwestie redakcyjne, np. watpliwości interpunkcyjne i inne, takie jak np. pre- i postpozycja przydawki oraz stylistyka. Każdorazowo wybrane osoby zapoznawaly się $z$ literaturą fachową $i$ dzielily się swoją wiedzą na dany temat $z$ resztą grupy wygłaszajac na forum referat i przedstawiajac przygotowana prezentację.

\section{W jaki sposób Unilex może wesprzeć mobilność studentów?}

Przedstawiony $\mathrm{w}$ artykule projekt thumaczenia niemieckiego slownika uniwersyteckiego na język polski i wyzwania z tym zwiazane pokazują że cel naszego projektu nie sprowadza się wylącznie do chęci podniesienia własnych kompetencji thumaczeniowych lub leksykograficznych. Celem nadrzędnym naszej pracy jest poszerzenie wiedzy studentów decydujacych się na realizację częśsi studiów w Niemczech, tak aby zdali sobie oni sprawę z różnic oraz podobieństw systemów szkolnictwa wyższego kraju ojczystego i kraju goszczącego. Mamy nadzieję, że bogatsi o tę wiedzę będą oni latwiej i szybciej wlączać się w życie niemieckiej spoleczności studenckiej. Jednocześnie zachęcamy studentów zrzeszonych w innych kolach naukowych do tworzenia podobnych slowników w innej parze językowej. $Z$ takich rezultatów pracy możecie nie tylko wy skorzystać, lecz także wasi koledzy i koleżanki. 


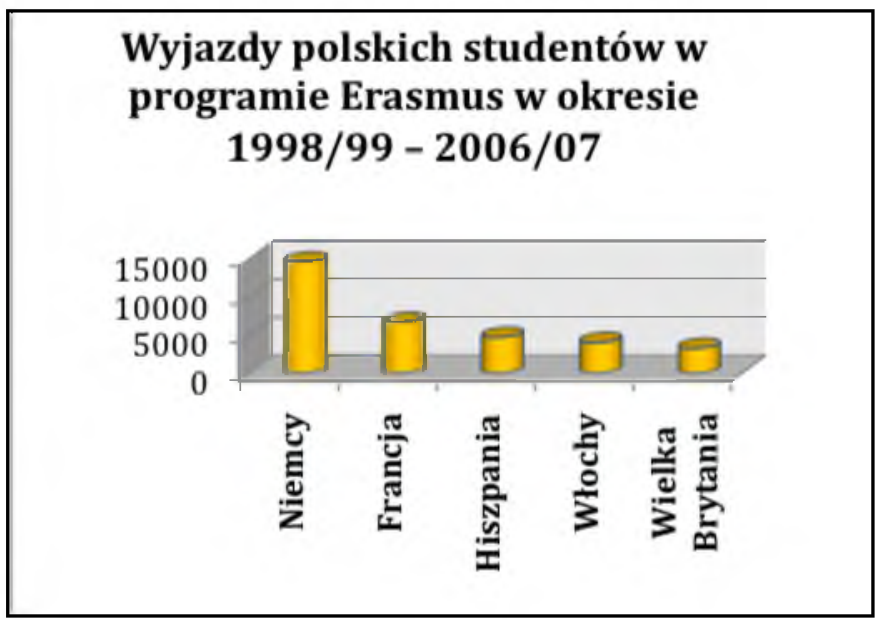

Opracowanie wlasne na podstawie publikacji: Fundacja Rozwoju Systemu Edukacji 2008. 10 lat Erasmusa w Polsce - wybór danych statystycznych i finansowych. Warszawa.

\section{Bibliografia}

DUW = Drosdowski, G. (ed.) 2004. Duden. Deutsches Universalwörterbuch. Mannheim: Dudenverlag.

FStDP $=$ Leksykon, Terminologia fachowa doradztwa podatkowego, rachunkowość, prawo podatkowe, prawo handlowe, część polsko niemiecka / Lexikon, Fachwörter für die Steuerberatung Deutsch-Polnisch, Rechnungswesen, Steuerrecht, Handelsrecht, 2002 Nürnberg/Krakau: DATEV eG. Klugert, B., Wojciechowski, K. 2001. Wörterbuch Deutsch-Polnisch. Begriffe aus Wissenschaft und Hochschule. Slownik polsko-niemiecki.

Kolanowska, E. 2008. 10 lat Erasmusa w Polsce - wybór danych statystycznych i finansowych. Warszawa. Fundacja Rozwoju Systemu Edukacji

Kroplewska, J. 2008. Die Entwicklung der Lehrerkompetenzen wahrend des Auslandsaufenthaltes im Rahmen des Erasmus-Programms. Poznań. Nieopublikowana praca licencjacka.

Natkowska, M. 2006. Od „numerus clausus” do getta lawkowego. Mówiq wieki, nr 5, 31-35. 
Schaeder, B., Rapti, A. 2008. Unilex Universitätswörterbuch für in- und ausländische Studierende. Siegen: Universität Siegen Fachberreich 3.

Schmidt, S. 2006. Kierunek Niemcy. Przewodnik dla zagranicznych studentów. Warszawa: Bizarre.

SJP PWN = Sobol, E. (red.). 2006. Stownik języka polskiego PWN. Warszawa: Wydawnictwo Naukowe PWN.

SWO = Kopaliński, W. 1994. Slownik wyrazów obcych. Warszawa: Wiedza Powszechna.

Turowska, J. 2007. Das Austauschprogramm ERASMUS als Beitrag zur Herausbildung interkultureller Kompetenz und einer europäischen Identität. Erfahrungen der Stipendiaten an der Universität Erfurt und an der Adam-Mickiewicz-Universität Poznań. Poznań. Nieopublikowana praca magisterska.

Umowa między Rządem Rzeczypospolitej Polskiej a Rządem Republiki Federalnej Niemiec o uznaniu ekwiwalencji w szkolnictwie wyższym sporządzona z dnia 23 lipca 1997 r. (Dz. U. z 1998 r. Nr 92, poz. $584)$. 